\title{
Macromolecular composition and anaerobic degradation of the sludge produced in a sequencing batch reactor
}

\author{
Susana Chelme \\ Departmento de Ingeniería Química \\ Universidad Católica del Norte \\ Av. Angamos 0610, Antofagasta, Chile \\ Tel: 5655355604 \\ Fax: 5655355917 \\ Pamela Fonseca \\ Departamento de Ingeniería Química \\ Universidad Católica del Norte \\ Av. Angamos 0610, Antofagasta, Chile \\ Tel: 5655355604 \\ Fax: 5655355917 \\ Rodrigo Mercado \\ Departamento de Ingeniería Química \\ Universidad Católica del Norte \\ Av. Angamos 0610, Antofagasta, Chile \\ Tel: 5655355604 \\ Fax: 5655355917 \\ Nelson Alarcon \\ Departamento de Ingeniería Química \\ Universidad Católica del Norte \\ Av. Angamos 0610, Antofagasta, Chile \\ Tel: 5655355604 \\ Fax: 5655355917 \\ E-mail: nalarcon@ucn.cl

\section{Omar Sánchez*} \\ Departamento de Ingeniería Química \\ Universidad Católica del Norte \\ Av. Angamos 0610, Antofagasta, Chile \\ Tel: 5655355604 \\ Fax: 5655355917 \\ E-mail: osanchez@ucn.cl
}

Financial support: Funding for this research was provided by FONDECYT 1050787, a grant from the Fondo Nacional de Desarrollo Científico y Tecnólogico (Chile).

Keywords: anaerobic digestion, sequencing batch reactor, sludge.

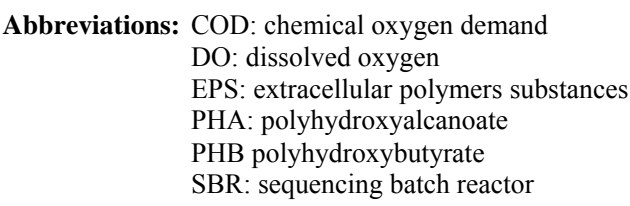

The effect of sequencing batch reactor (SBR) operating conditions on sludge macromolecular composition and the effect of sludge macromolecular composition on the anaerobic degradation of the sludge produced in SBR was investigated in this work. A SBR, fed with synthetic wastewater, was operated at different air flow rates. The resulting sludge was analyzed in terms of protein, carbohydrate, phospholipid and polyhydroxybutyrate concentrations. Methane production during anaerobic digestion of the sludge was also measured. Ammonium, nitrite, nitrate, dissolved oxygen and chemical oxygen demand (COD) track studies in the SBR were carried out in order to relate SBR performance and sludge macromolecular composition. The lowest air flow rate at which the SBR was operated was $21 \mathrm{~min}^{-1}$, in which case the dissolved oxygen concentration was lower than

*Corresponding author 
$0.5 \mathrm{mg} \mathrm{l-1}$ in the SBR and partial denitrification occurred during the feeding phase. An increased air flow rate caused a decrease in protein concentration, as well as an increase in carbohydrate concentration. Polyhydroxybutyrate (PHB) concentration in the sludge was independent of air flow rate. At different air flows, the methane production rates were similar, but the total volume of methane was greater during anaerobic digestion of the sludge produced at low air flow rates. These results indicate a strategy by which changes in sludge composition can optimize the operation of anaerobic sludge digesters.

Sequencing batch reactors (SBR) are a proven technology for efficient carbon and nitrogen removal from domestic and industrial wastewaters (Kim et al. 2004). This technology is flexible for operation and accommodates load variations. A typical operation cycle includes several stages: feeding, reaction, mixed liquor withdrawal, settling and supernatant withdrawal. The feeding and reaction stages can be controlled to promote aerobic and anoxic microbial reactions. These reactions can occur either in sequential form (Kim et al. 2004; Beline et al. 2007) or simultaneously (Pochana and Keller, 1999), depending on the dissolved oxygen concentration in the SBR (Pochana and Keller, 1999; Third et al. 2003). This versatility has allowed the implementation of SBR under different operating strategies; the scheduling of the various stages may be altered, and likewise for the feeding and control strategies, the latter of which can optimize carbon and nitrogen removal.

For the removal of carbon and nitrogen from wastewaters, the high sludge production is one of the main drawbacks of both the SBR technology and the activated sludge systems. The treatment or disposition of the sludge produced in SBR represents an important operating cost of the wastewater treatment plants that use SBR technology.

Anaerobic digestion is commonly used in wastewater plants to treat the secondary sludge byproduct, and has received considerable attention. There have been several studies on the mathematical modelling of sludge anaerobic digestion, the enhancement of anaerobic digestion via pre-treatment, and the optimization of process conditions (Kim et al. 2002; Vlyssides and Karlis, 2004; Soteman et al. 2005). It is known that the kinetics of anaerobic digestion of organic solids depends on their composition (Parkin and Owen, 1986). The hydrolysis of carbohydrates, proteins and lipids occurs at different rates (Grady et al. 1999) and hydrolysis is the rate limiting step in the anaerobic digestion of sludge (Torre and Stephanopoulos, 1986). Previous studies have demonstrated that the macromolecular composition of microbial biomass formed in the continuous reactors depends on reactor operating conditions (Abbot et al. 1984; Hanegraaf and Muller, 2001). The principal components of activated sludge flocs are bacteria and extracellular polymers substances (EPS). Determination of the chemical composition of EPS has been the objective of many

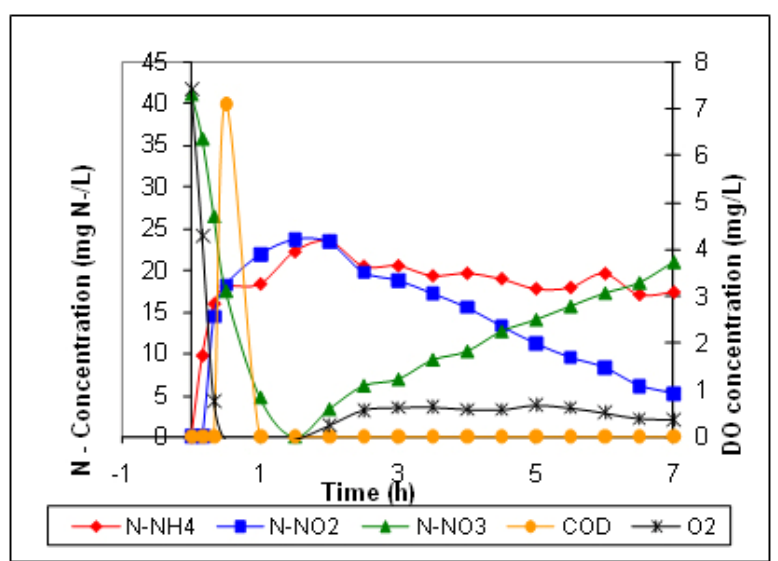

Figure 1. COD and ammonium, nitrite, nitrate and dissolved oxygen concentration profiles at air flow of 2 L/min.

research papers (Frolund et al. 1996; Dignac et al. 1998; Sponza, 2003), thus proteins and carbohydrates have been identified as the principal components of EPS (Comte et al. 2006). Considerably less attention has been devoted to the influence of macromolecular composition of sludge on anaerobic digestion. This study provides valuable information regarding the influence of sludge macromolecular composition on the anaerobic digestion rate.

The principal macromolecules in activated sludge flocs are proteins, carbohydrates and lipids. However, intracellular storage of organic matter as polyhydroxyalcanoate (PHA) in SBR can be significant since biomass grows under dynamic conditions (Majone et al. 1999; Third et al. 2003). Thus, depending on the operating conditions, the sludge could contain a significant amount of PHA. Alternative SBR operation strategies may reduce sludge production or increase the sludge anaerobic conversion rate, and in either case the wastewater treatment cost is diminished.

Several works have described the effect of dissolved oxygen concentration on the conversion of organic matter and nitrogen in SBR (Dangcong et al. 2000; Third et al. 2003; Hu et al. 2005). Dissolved oxygen concentration has been identified as an important parameter to control simultaneous nitrification, denitrification and nitrite accumulation in SBR (Pochana and Keller, 1999; Rhee et al. 1997). Sludge macromolecular composition has been monitored in continuous activated sludge systems (Frolund et al. 1986; Dignac et al. 1998; Sponza, 2003), in order to determine the macromolecular composition of the EPS. To date the study of the relationship between SBR operating conditions and sludge macromolecular conditions have received little attention.

The objectives of this work were: a) to assess the effect of SBR operating conditions on sludge macromolecular composition; b) to assess the effect of sludge 


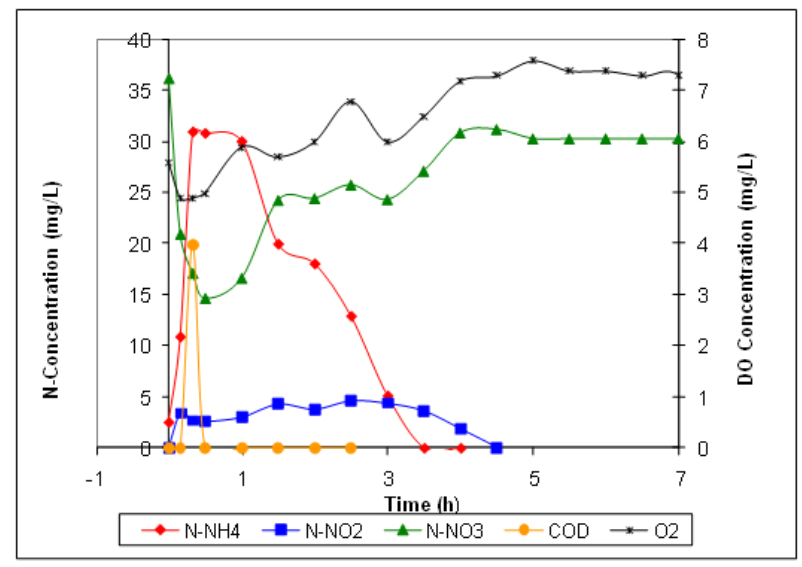

Figure 2. COD and ammonium, nitrite, nitrate and dissolved oxygen concentration profiles at air flow of $3 \mathrm{~L} / \mathrm{min}$.

macromolecular composition on the anaerobic degradation of the sludge produced in SBR. The study was designed to provide experimental data for the optimization of sludge anaerobic digestion via manipulation of the sludge composition. As dissolved oxygen concentration is a useful parameter to control carbon and nitrogen removal, an SBR was operated at different dissolved oxygen concentrations, and the resulting sludge was analyzed for macromolecular composition. Ammonium, nitrite, nitrate, dissolved oxygen and chemical oxygen demand (COD) track studies in the SBR were carried out in order to relate SBR performance and sludge macromolecular composition.

\section{MATERIALS AND METHODS}

\section{Sequencing batch reactor}

Experiments were carried out in a lab scale SBR with a total cycle time of $8 \mathrm{hrs}$, consisting of the following sequence: feeding (30 min), reaction (390 min), settling (30 $\mathrm{min})$ and supernatant withdrawal $(30 \mathrm{~min})$. Air injection was only provided for the feeding and reaction periods. During the start-up period (65 days) the air flow rate was regulated at $41 \mathrm{~min}^{-1}$. The initial reactor volume was 1.61 and the working volume was 31 . The temperature was kept at $30^{\circ} \mathrm{C}$ and the $\mathrm{pH}$ was controlled between 7 and 7.5. The reactor was constantly mixed during the feeding and reaction periods. The synthetic wastewater fed to the reactor contained $0.64 \mathrm{~g}^{-1} \mathrm{CH}_{3} \mathrm{COONa} 3 \mathrm{H}_{2} \mathrm{O}(300 \mathrm{mg}$ $\left.\mathrm{COD} \mathrm{l}^{-1}\right), 0.236 \mathrm{~g} \mathrm{l}^{-1}\left(\mathrm{NH}_{4}\right)_{2} \mathrm{SO}_{4}\left(50 \mathrm{mg} \mathrm{N}-\mathrm{NH}_{4}{ }^{+}{ }^{-1}\right)$ and 10 $\mathrm{ml} \mathrm{l}^{-1}$ of a micronutrient solution. The solid retention time was 4.2 days and the hydraulic retention time was 0.35 days.

To relate SBR performance and sludge macromolecular composition, the SBR was operated with air flow rates ranging from 2 to $51 \mathrm{~min}^{-1}$. SBR performance was assessed by conducting track studies following the conversion of acetate and ammonium during the cycle. Samples from the
SBR were collected periodically over the entire development of each cycle, whereby COD, ammonium, nitrite and nitrate concentration were measured. Dissolved oxygen (DO) concentration was measured online. Upon completion of the reaction phase at fixed air flow rate, a sludge sample was collected for the anaerobic digestion experiment. The carbohydrate, protein, phospholipid and polyhydroxybutyrate (PHB) content of the sludge sample were measured.

\section{Analytical methods}

Proteins were measured using the Lowry method (Lowry et al. 1951). The Dubois method was applied for carbohydrate determination (Dubois et al. 1956) and phospholipids were determined according to a procedure developed for biofilm (Michaud et al. 2003). Polyhydroxybutyrate was determined using the gas-chromatographic method (Riis and Mai, 1988). Ammonium, nitrite and nitrate were measured by ionic chromatography (Shimadzu, HIC-6A, Japan). Dissolved oxygen concentration was monitored online using a DO meter (Cole Parmer, Model 01972-00, USA) coupled to a data acquisition system (Iotech, Personal DAQ/55, USA).

During the anaerobic digestion experiment, the methane production was measured using a method described by Soto et al. (Soto et al. 1993). The experiments were performed in a batch reactor with aerobic sludge formed in the SBR at different DO concentrations and anaerobic sludge from a full scale UASB used to treat brewery wastewater. Before the experiments, the anaerobic granules were ground. The aerobic and anaerobic sludge concentrations in the anaerobic digester were $1 \mathrm{~g} \mathrm{l}^{-1}$ and $3 \mathrm{~g} \mathrm{l}^{-1}$, respectively. Temperature was kept constant at $37^{\circ} \mathrm{C}$. Sodium carbonate was added $\left(1.5 \mathrm{~g} \mathrm{l}^{-1}\right)$ to provide buffer capacity thus avoiding a decrease in $\mathrm{pH}$. Methane was measured by acidified water $(\mathrm{pH}=4)$ displacement.

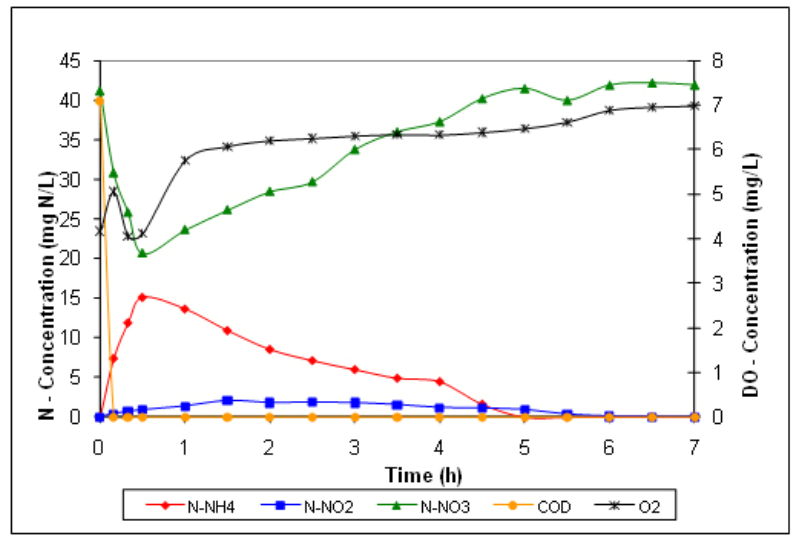

Figure 3. COD and ammonium, nitrite, nitrate and dissolved oxygen concentration profiles at air flow of $4 \mathrm{~L} / \mathrm{min}$. 


\section{RESULTS AND DISCUSSION}

The SBR was operated for 65 days under constant operating conditions prior to experimentation, with an air flow of $4 \mathrm{~L} \mathrm{~min}^{-1}$. After 65 days, the VS reached a mean value of $1.3 \mathrm{~g} \mathrm{l}^{-1}$. Ammonium and nitrite were not detected in the reactor effluent.

\section{SBR performance at an air flow of $2 \mathrm{I} \mathrm{min}^{-1}$}

Profile of DO concentrations during a cycle in SBR depends on the balance between the rate of oxygen consumption (via the oxidation of ammonium and organic matter) and the oxygen transfer rate from air to liquid. When the SBR was operated at an air flow rate of $21 \mathrm{~min}^{-1}$, DO concentration was low during the entire cycle (Figure 1), and therefore the sludge was formed under low DO concentration conditions.

Partial denitrification occurred at the beginning of the cycle (Figure 1). The nitrate initially present in the reactor was completely transformed into nitrite. This indicates that the reduction rate of nitrate was greater than that of nitrite and that these two reductions did not occur simultaneously. The nitrogen balance reveals that during the feeding phase, ammonia conversion by nitrification was very low, hence the accumulation of ammonium. After the acetate was depleted, the DO concentration increased and nitrite and ammonium concentration began to decrease. The nitrite produced by partial denitrification was oxidized to nitrate with a greater rate than the ammonium oxidation.

The simultaneous nitrate reduction and storage of acetate as PHB is known to occur when acetate is added to an SBR under anoxic conditions during the feeding phase (Beun et al. 2000; Dionisi et al. 2001). In the present work, air was injected into the SBR during the feeding phase, yet nitrate conversion into nitrite occurred during the cycle even with an air flow rate of $21 \mathrm{~min}^{-1}$ in the SBR. Acetate can be

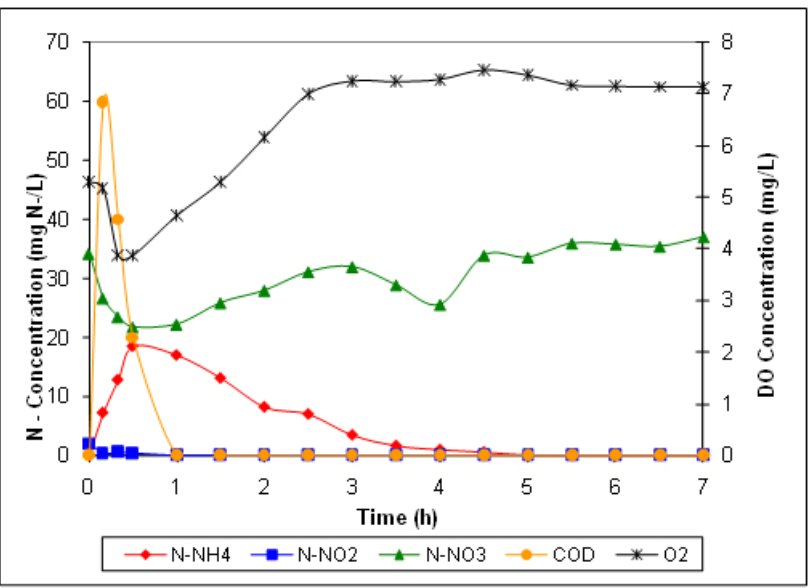

Figure 4. COD and ammonium, nitrite, nitrate and dissolved oxygen concentration profiles at air flow of $5 \mathrm{~L} / \mathrm{min}$. transformed by bacteria either through the PHB route or the TCA cycle (Beun et al. 2002). If acetate is transformed through the PHB route, then the resulting PHB must become the carbon-electron source for the reduction of nitrate and nitrite. Denitrification using PHB as an electron donor is a slow process (Third et al. 2003), and when PHB is the only available carbon source for denitrification, it has been observed that the nitrite reduction rate is lower than that of nitrate (Beun et al. 2000; Dionisi et al. 2001). If acetate is transformed through the TCA cycle, denitrification is promoted by the availability of reductant. Thus, substrate storage could be a viable mechanism to explain nitrite accumulation during an anoxic or low DO concentration SBR feeding phase.

\section{SBR performance at an air flow of 3,4 , and 5 I $\min ^{-1}$}

In the experiments carried out at air flow rates of 3, 4 and 5 $1 \mathrm{~min}^{-1}$, complete nitrification occurred without any denitrification (Figure 2, Figure 3 and Figure 4). Nitrite accumulation was low, and nitrite concentration reached a maximum value of $2.5 \mathrm{mg} \mathrm{N}-\mathrm{NO}_{2}{ }^{-} \mathrm{l}^{-1}$ when the SBR was operated at an air flow of $31 \mathrm{~min}^{-1}$. When the SBR was operated at an air flow of $21 \mathrm{~min}^{-1}$, the sludge was formed under low DO concentration. Running the cycle at 3,4 , and $51 \mathrm{~min}^{-1}$ caused the DO concentration to exceed $4 \mathrm{mg} \mathrm{l}^{-1}$ during the entire cycle, and therefore the sludge was formed under high DO concentration.

\section{Sludge macromolecular composition and anaerobic digestion}

Experimental data of macromolecular sludge composition for different air flow rates are shown in Figure 5. Protein and carbohydrate concentration in the sludge ranged from 150 to $240 \mathrm{mg} \mathrm{g}^{-1} \mathrm{SSV}$ and from 200 to $400 \mathrm{mg} \mathrm{g}^{-1} \mathrm{SSV}$, respectively. PHB concentration was very much lower, ranging between 10 and $24 \mathrm{mg} \mathrm{g}^{-1} \mathrm{SSV}$. Thus proteins and carbohydrates were the main components of the sludge formed in the SBR. Protein decreased with the air flow rate, whereas carbohydrate concentration increased with the air flow rate. PHB concentration in the sludge was practically constant. For an SBR fed with acetate as a carbon source, it had been reported that PHB content would increase when the oxygen supply rate was increased (Third et al. 2003). However, PHB had only been measured until the acetate was depleted, and the PHB content of the sludge at the end of the cycle was not reported. PHB can be metabolized under aerobic conditions (Majone et al. 1999). It has been reported that initially during a cycle in SBR, the PHB was synthesized until the external substrate is depleted (Soteman et al. 2005). Then, the internally stored PHB was used as a substrate, and PHB concentration in the sludge decreased, but PHB was still detected at the end of the cycle.

PHB can be used as an electron donor for denitrification, when appropriate external electron donors are not available 

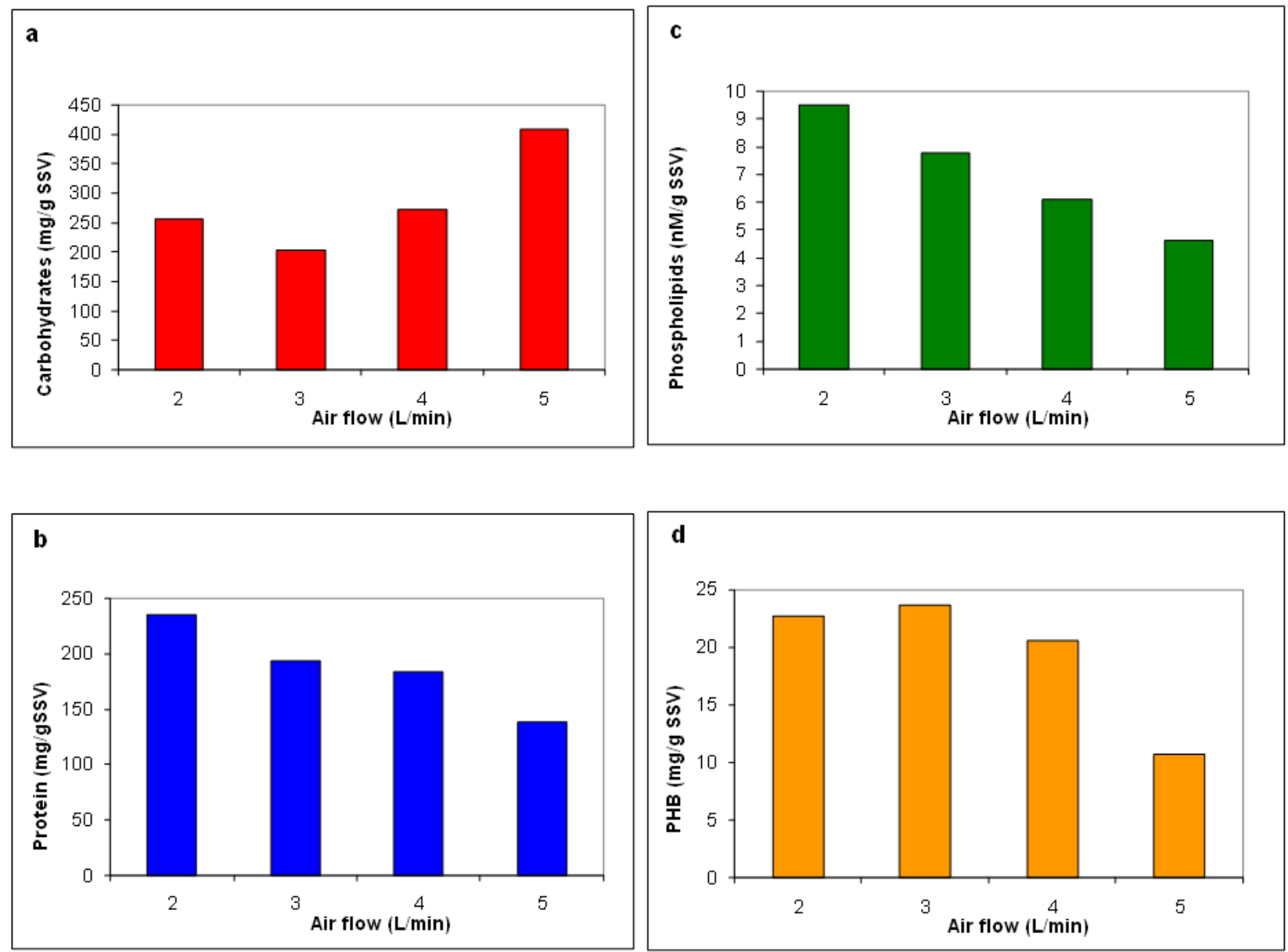

Figure 5. Macromolecular composition of the sludge in the SBR at different air flow.

(a) Carbohydrates.

(b) Protein.

(c) Phospholipids.

(d) PHB.

(Beun et al. 2000). Storage induced denitrification has been investigated for efficient carbon and nitrogen removal since the organic matter present in low $\mathrm{C} / \mathrm{N}$ wastewater could be stored as PHB during the aerobic phase, and these PHB could then be used during a next anoxic phase for denitrification of the nitrate produced under aerobic conditions by nitrification (Alleman and Irvine, 1980; Third et al. 2003). In the present work, storage induced denitrification was not observed when the cycle was operated at an air flow rate of $21 \mathrm{~min}^{-1}$. The nitrite present when the acetate was depleted was converted into nitrate by nitrite oxidizing bacteria.

Figure 6 displays the methane production during the anaerobic digestion of sludge produced in the SBR at different air flow rates. Due to a failure in the operation of the SBR with an air flow of $51 \mathrm{~min}^{-1}$, it was not possible to collect sludge to carry out the anaerobic digestion experiment. Initially the volume of methane produced increased lineally. The methane production rate was taken to be the slope of the linear section of the curve, which was not influenced by the air flow rate in the SBR. However, the net amount of methane produced increased when the air flow rate was lowered. PHB concentrations in the sludge were much lower than the concentrations of carbohydrates and proteins, which became the main substrates for anaerobic digestion and methane production.

Sequencing batch reactors are increasingly used for the removal of organic matter and nitrogen from wastewater, and are commonly used for the anaerobic degradation of excess sludge. The methane generated during sludge anaerobic digestion may be used as a fuel, so the digesters are designed to maximize methane production. It is now suggested that SBR could be controlled to further enhance methane production during the subsequent anaerobic digestion.

\section{CONCLUDING REMARKS}

The macromolecular composition of the sludge formed in an SBR operated at different dissolved oxygen 


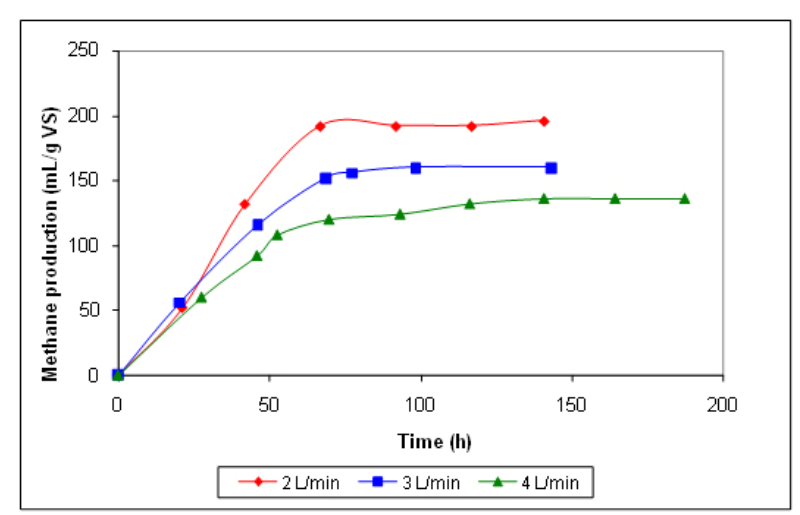

Figure 6. Methane production from the sludge produced in the SBR at different air flow.

concentrations was measured, and the anaerobic digestion of this sludge was carried out in order to relate sludge macromolecular composition to the anaerobic digestion rate. Protein concentration in the sludge was greater at low air flow rates, whereas carbohydrates concentration was greater at high air flow rates. However, PHB concentration in the sludge was practically independent of air flow rate. Maximum methane production was obtained during anaerobic digestion of the sludge formed under the low air flow rates. This generally suggests that low air flow rates in the SBR (and hence high protein content) result in high methane yield in the subsequent anaerobic digestion. Thus the consideration of sludge macromolecular composition indicates optimal operation strategies for anaerobic sludge digesters.

\section{REFERENCES}

ABBOT, B.; LASKIN, A. and McCOY, C. Effect of growth rate and nutrient limitation on the composition and biomass yield of Acinetobacter calcoaceticus. Applied Microbiology, 1984, vol. 28, no. 1, p. 58-63.

ALLEMAN, J. and IRVINE, R. Storage induced denitrification using sequencing batch reactor operation. Water Research, 1980, vol. 14, no. 10, p. 1483-1488.

BELINE, F.; BOURSIER, H.; DAUMER, M.; GUIZIOU, F. and PAUL, E. Modeling of biological process during aerobic treatment of piggery wastewater aiming at process optimization. Bioresource Technology, 2007, vol. 98, no. 17, p. 3298-3308.

BEUN, J.; DIRCKS, K.; LOOSDRECHT, M.C.M. and HEIJNEN, J. Poly- $\beta$-hydroxybutyrate metabolism in dynamically fed mixed microbial cultures. Water Research, 2002, vol. 36, no. 5, p. 1167-1180.

BEUN, J.; VERHOEF, E.; LOOSDRECHT, M.C.M. and HEIJNEN, J. Stoichiometry and kinetics of poly- $\beta$ hydroxybutyrate metabolism under denitrifying conditions in activated sludge cultures. Biotechnology and Bioengineering, 2000, vol. 68, no. 1, p. 496-507.

COMTE, S.; GUIBAUD, G. and BAUDU, M. Relations between extraction protocols for activated sludge extracellular substances (EPS) and EPS complexation properties. Part I. Comparison of the efficiency of eight extraction procedures. Enzyme and Microbial Technology, 2006, vol. 38, no. 1-2, p. 237-245.

DANGCONG, P.; BERNET, N.; DELGENES, J.P. and MOLETTA, R. Effects of oxygen supply methods on the performance of sequencing batch reactor for high ammonia nitrification. Water Environmental Research, 2000, vol. 72, no. 2, p. 195-200.

DIGNAC, M.; URBAIN, V.; RYBACKI, D.; BRUCHET, A.; SNIDARO, D. and SCRIBE, P. Chemical description of extracellular polymers: Implication on activated sludge floc structure. Water Science and Technology, 1998, vol. 38, no. $8-9$, p. 45-53.

DIONISI, D.; MAJONE, M.; RAMADORI, R. and BECCARI, M. The storage of acetate under anoxic conditions. Water Research, 2001, vol. 35, no. 11, p. 26612668 .

DUBOIS, M.; GILLES, K.; HAMILTON, J.; SEBERS, P. and SMIITH, F. Colorimetric method for determination of sugars and related substances. Analytical Chemistry, 1956, vol. 28 , no.3, p. 350-356.

FROLUND, B.; PALMGREM, R.; KEIDING, K. and NIELSEN, P. Extraction of extracellular polymers from activated sludge using a cation exchange resin. Water Research, 1996, vol. 30, no. 8, p. 1749-1758.

GRADY Jr, CPL.; DAIGGER, G. and LIM, H. Biological wastewater treatment. New York, $2^{\text {nd }}$ ed, Marcel Dekker, Inc., 1999. 1092 p. ISBN 0824789199.

HANEGRAAF, P. and MULLER, E. The dynamics of the macromolecular composition of biomass. Journal of Theoretical Biology, 2001, vol. 212, no. 2, p. 237-251.

HU, L.; WANG, J.; WEN, X. and QIAN, Y. Study on performance characteristics of SBR under limited dissolved oxygen. Process Biochemistry, 2005, vol. 40, no.1, p. 293296.

KIM, M.; AHAN, Y. and SPEECE, R. Comparative process stability and efficiency of anaerobic digestion, mesophilic v.s thermophilic. Water Research, 2002, vol. 36 , no. 17 , p. $4369-4385$.

KIM, J.; CHEN, M.; KISHIDA, N. and SUDO, R. Integrated real-time control strategy for nitrogen removal in swine wastewater treatment using sequencing batch reactors. Water Research, 2004, vol. 38, no. 14-15, p. 33403348. 
LOWRY, O.; ROSENBROUGH, N.; FARR, A. and RANDALL, R. Protein measurement with the Folin-phenol reagent. Journal Biological Chemistry, 1951, vol. 193, no. 1, p. 265-275.

MAJONE, M.; DIRCKS, K. and BEUN, J. Aerobic storage under dynamic conditions in activated sludge processes. The state of the art. Water Science and Technology, 1999, vol. 39, no. 1, p. 61-73.

MICHAUD, S.; BERNET, N.; ROUSTAN, M.; DELGENES, JP. Influence of hydrodynamic conditions on biofilm behaviour in a methanogenic inverse turbulent bed reactor, Biotechnology Progress, 2003, vol. 19, no. 3, p. 858-863.

PARKIN, G. and OWEN, W. Fundamentals of anaerobic digestion of wastewater sludges. Journal of Environmental Engineering, 1986, vol. 12, no. 2, p. 867-920.

POCHANA, K. and KELLER, J. Study of factors affecting simultaneous nitrification and denitrification (SND). Water Science and Technology, 1999, vol. 39, no. 6, p. 61-68.

RHEE, S.; LEE, J. and LEE, S. Nitrite accumulation in a sequencing batch reactor during the aerobic phase of nitrogen removal. Biotechnology Letters, 1997, vol. 19, no. 2, p. 195-198.

RIIS, V. and MAI, W. Gas chromatographic determination of poly- $\beta$-hydroxybutyric acid in microbial biomass after hydrochloric acid propanolysis. Journal of Chromatography A, 1988, vol. 445, p. 285-289.

SOTEMAN, S.; RISTOW, N.; WENTZEL, M. and EKAMA, G. A steady state model for anaerobic digestion of sewage sludges. Water SA, 2005, vol. 31, no. 4, p. 511527.

SOTO, M.; MENDEZ, R. and LEMA, J.M. Methanogenic and non-methanogenic activity test. Theoretical basis and experimental set up. Water Research, 1993, vol. 27, no. 8, p. 1361-1376.

SPONZA, D. Investigation of extracellular polymer substances (EPS) and physicochemical on different activated sludge flocs under steady state conditions. Enzyme and Microbial Technology, 2003, vol. 32, no. 3-4, p. 375-385.

THIRD, K.; NEWLAND, M. and CORD-RUWISCH, R. The effect of dissolved oxygen in PHB accumulation in activated sludge cultures. Biotechnology and Bioengineering, 2003, vol. 82, no.2, p. 238-250.

TORRE, A. and STEPHANOPOULOS, G. Mixed culture model of anaerobic digestion: Application to the evaluation of start up procedures. Biotechnology and Bioengineering, 1986, vol. 28, no. 7, p. 1106-1118.
VLYSSIDES, A.; KARLIS, P. Thermal-alkaline solubilization of waste activated sludge as a pre-treatment stage for anaerobic digestion. Bioresource Technology, 2004, vol. 91, no. 2, p. 201-206. 